\title{
The Danish Twin Registry in the New Millennium
}

\author{
Axel Skytthe,' Kirsten Kyvik,' Lise Bathum,' Niels Holm,' James W. Vaupel, ${ }^{2}$ and Kaare Christensen' \\ ' The Danish Twin Registry, Epidemiology, Institute of Public Health, University of Southern Denmark, Odense, Denmark \\ ${ }^{2}$ Max Planck Institute for Demographic Research, Rostock, Germany
}

$T^{\text {tom }}$ he Danish Twin Registry is the oldest national twin register in the world, initiated in 1954, and, by the end of 2005 , contained more than 75,000 twin pairs born in the between 1870 and 2004. The Danish Twin Registry is used as a source for studies on the genetic influence on normal variation in clinical parameters associated with the metabolic syndrome and cardiovascular diseases, clinical studies of specific diseases, and aging and agerelated health problems. The combination of survey data, clinical data and linkage to national healthrelated registers enables follow-up studies of both the general twin population and twins from clinical studies. This paper summarizes the newest extension of the register and gives examples of new developments and phenotypes studied.

Established in 1954, the Danish Twin Registry (DTR) is the oldest nationwide twin register in the world and also the twin register with the largest coverage of birth cohorts (Skytthe et al., 2002). At the end of 2005 , more than 75,000 twin pairs born in the period 1870 to 2004 were included in the DTR.

The DTR serves as a basis for multidisciplinary research and exploits a number of different study designs. One major part of this research is founded on interview-based surveys, primarily among the middleaged and elderly twins, along with biological samples for genetic studies. Questionnaire-based surveys have been conducted for younger and middle-aged twins during the last 5 years. Furthermore, clinically and biochemically orientated studies of subsamples of twins have aimed at disentangling the genetics behind the metabolic syndrome and related conditions, for example, the GEMINAKAR project (Hansen et al., 2004; Schousboe et al., 2003). Finally, increased uses of national registers has led to a number of registerbased studies, where all twins alive in 1968 or later have served as a base for studies on general and specific health conditions as well as comparative studies of twins and singletons.

This article presents various examples of research topics across a range of age groups, illustrating the diverse insight provided when utilizing twin methodology.

\section{New Cohorts Added to DTR}

The DTR is updated regularly with new multiple birth cohorts. The source is the national Medical Birth Registry, where all births in Denmark are registered. Almost all births in Denmark take place in hospitals or special birth clinics closely connected to hospitals, and since 1996 birth characteristics are recorded through the Danish National Register of Patients. Both live-born and stillborn children are registered, and consequently the DTR includes both liveand stillborn twins and triplets.

The youngest birth cohort presently included is from 2004. Table 1 presents the distribution of multiple births in the period 1983 to 2004. In the early 1980 s the twin birth rate was the lowest ever recorded in Denmark, with only about 1 in 100 births a multiple birth (Figure 1). Since the late 1980s the rate of multiple births has increased dramatically, primarily due to the increased use of assisted reproductive technology (in vitro fertilization [IVF], hormone treatment, and so on), but recent studies have also indicated an increase in the naturally conceived twin birth rate in Denmark (Herskind et al., 2005). The increase in twin birth rate is expected to plateau, however, as single egg transfer during IVF will become more common in the future than double egg transfer. A similar trend is observed for the triplet birth rate, which has decreased due to recommendation from the National Board of Health in 1997 to transfer only two fertilized eggs instead of three.

\section{National Twin Surveys}

A key issue in twin studies is the assessment of the zygosity of the twins. For birth cohorts up to 1982, zygosity was assessed at the time of enrolment in the twin registry by means of a questionnaire, where four questions about the similarity between same-sexed twins have been used to separate monozygotic (MZ) and dizygotic (DZ) twins. Previous studies have shown

\section{Received 1 August, 2006; accepted 9 September, 2006}

Address for correspondence: Axel Skytthe, The Danish Twin Registry, University of Southern Denmark, J B Winløws Vej 9 B, DK-5000 Odense C., Denmark.E-mail: askytthe@health.sdu.dk 
Table 1

Distribution of Multiple Births in Denmark 1983-2004

\begin{tabular}{|c|c|c|c|c|c|c|}
\hline Birth cohorts & $\mathrm{FF}$ & FM & MM & Unknown & Triplets and higher & Total \\
\hline 1983-1987 & 939 & 822 & 1020 & 0 & 124 & 2905 \\
\hline 1988-1992 & 1298 & 1210 & 1216 & 0 & 207 & 3931 \\
\hline 1993-1997 & 1656 & 2097 & 1839 & 110 & 183 & 5885 \\
\hline 1998-2002 & 1901 & 2499 & 2029 & 121 & 116 & 6666 \\
\hline 2003-2004 & 846 & 1055 & 859 & 0 & 57 & 2817 \\
\hline 1983-2004 & 6640 & 7683 & 6963 & 231 & 687 & 22,204 \\
\hline
\end{tabular}

Note: Twin pairs with stillborn twins are included.

$\mathrm{FF}=$ female-female twins, $\mathrm{FM}=$ female-male twins, $\mathrm{MM}=$ male-male twins.

that the zygosity is assigned correctly in about $95 \%$ of all same-sexed twin pairs using the questionnaire method (Christiansen et al., 2003; Hauge, 1981).

The identification and registration of twins of birth cohorts from 1983 onwards have been done by extracts from the Medical Birth Register. The 2003 twin survey conducted on the 1983-2000 birth cohorts included the four similarity questions in order to assess the zygosity of these younger twins. The survey was divided into two parts; twins born before 1988 were approached directly (2582 twin pairs), while the questionnaire was sent to the parents of younger twins (12,277 twin pairs), meaning that the similarity questions were answered primarily by the twins in the oldest birth cohorts and solely by the parents in the younger cohorts. The overall response rate was $68 \%$, and the result of the zygosity assessment is shown in Table 2.

The 2003 twin survey also collected information for a series of ongoing research projects with focus on incidence of child conditions like asthma, febrile seizures, epilepsies, and diabetes type I. In addition, the questionnaire contained an item about possible fertility treatment in order to estimate the proportion of twins in the register born of 'natural' twinning versus twins resulting from infertility treatment procedures. A register of initiated IVF and/or intracytoplasmic sperm injection fertility treatment in Denmark was established in 1994 (Pinborg et al., 2004), but use of these technologies was undertaken several years prior to this, which can also be seen in the increased rate of twin births. Furthermore, not every kind of fertility

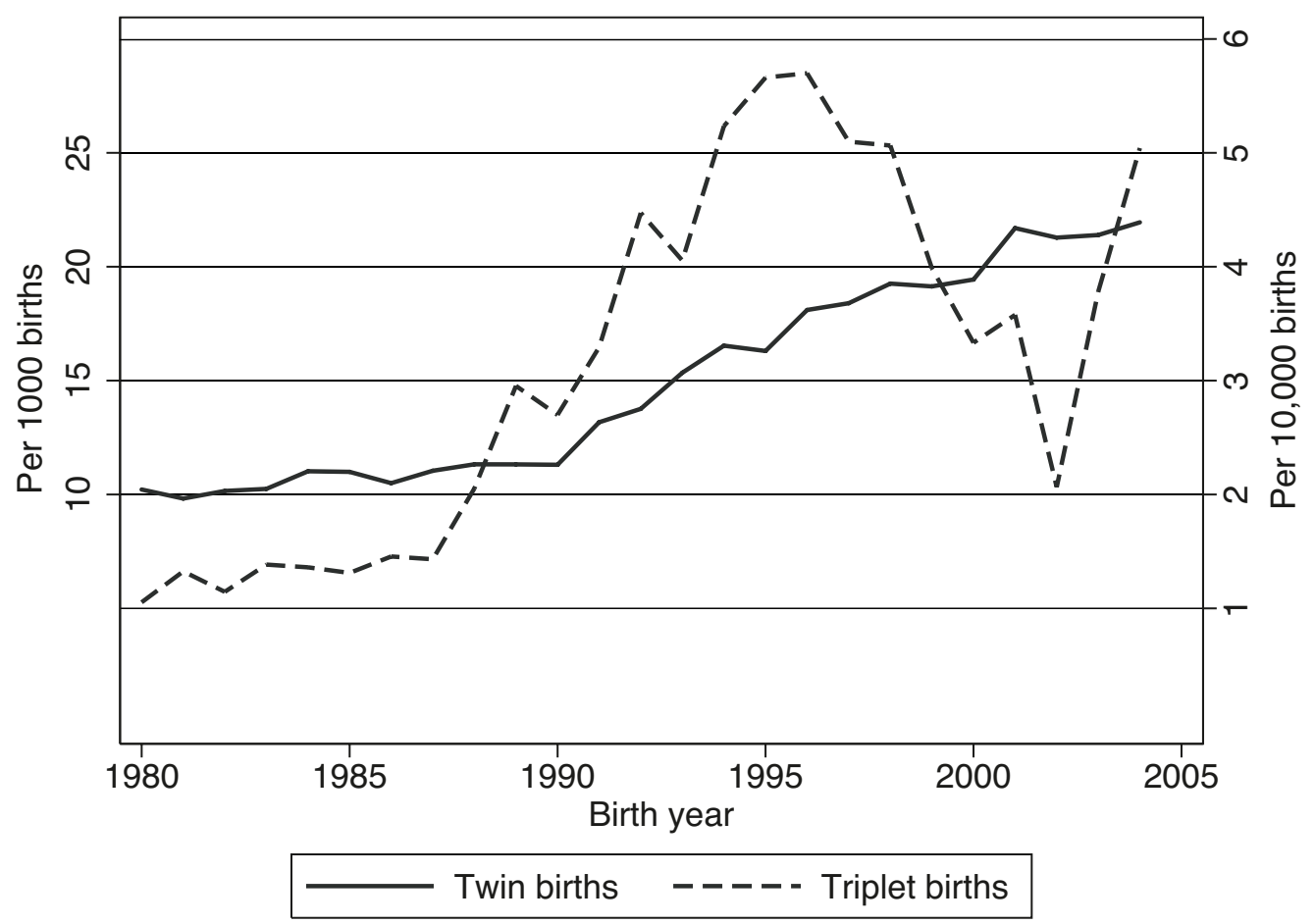

Figure 1

Twin birth rate per 1000 births (left axis) and triplet birth rate per 10,000 births (right axis) in Denmark from 1980 to 2004. 
Table 2

Zygosity Assessment Based on Four Similarity Questions - Twin Survey 2003

\begin{tabular}{lcccccc}
\hline Birth cohorts & MZ & DZ-SS & UZ-SS & DZ-OS & Triplets & Total \\
\hline $1983-1987$ & $369(14.3)$ & $673(26.1)$ & $770(29.8)$ & $767(29.7)$ & $3(0.1)$ & 2582 \\
$1988-2000$ & $1400(11.4)$ & $3509(28.6)$ & $2865(23.3)$ & $4483(36.5)$ & $20(0.2)$ & 12,277 \\
$1983-2000$ & $1769(11.9)$ & $4182(28.1)$ & $3635(24.5)$ & $5555(35.3)$ & $23(0.2)$ & 14,859 \\
\hline
\end{tabular}

Note: Number of twin pairs with per cent of total in parentheses.MZ = monozygotic; DZ-SS = dizygotic, same-sexed; UZ-SS = unknown zygosity, same-sexed; DZ-0S = dizygotic, opposite-sexed twins.

treatment is included in the registry. The 2003 twin survey will make it possible to estimate the proportion of twin births that have resulted from any kind of assisted reproductive technology prior to 1994 (Figure $3)$. The proportion of twin births from fertility treatment increased during the 1990 s to almost $50 \%$ of all twin births, in accordance with the increase in twin birth rate shown in Figure 1.

Another twin survey, using the DTR, was conducted in 2002 to address issues of health and health-related behavior, fertility, socioeconomic characteristics (e.g., education and occupation), and subjective well-being. All twins born between 1931 and 1982 were surveyed, with 34,944 twins returning completed questionnaires (a response rate of $75 \%$ ). The results from this survey have been used both as a screening tool to identify subgroups of twins for more detailed studies of specific diseases (e.g., club foot; Engell et al., 2006) and for studies of cohorts of twins (e.g., neck pain, Fejer et al., 2006; fertility and subjective well-being, Kohler et al., 2005).

\section{Twin Studies on Aging}

Over the last 10 years biological indicators and genetic information have been added to our ongoing longitudinal surveys among middle-aged and elderly twins in order to get a better understanding of the predictors and determinants of healthy aging. Two different strategies were set to collect biological indicators in these studies. First, it was decided to collect a few easily obtainable biological indicators from nearly all participants in the surveys to be able to make valid and statistically powerful tests of new findings from other studies - in particular, genetic association studies which comprise a research field that suffers from many false positive findings due to multiple testing in many small scale studies. Second, it was decided to obtain more detailed biological indicators from individuals who were identified through the

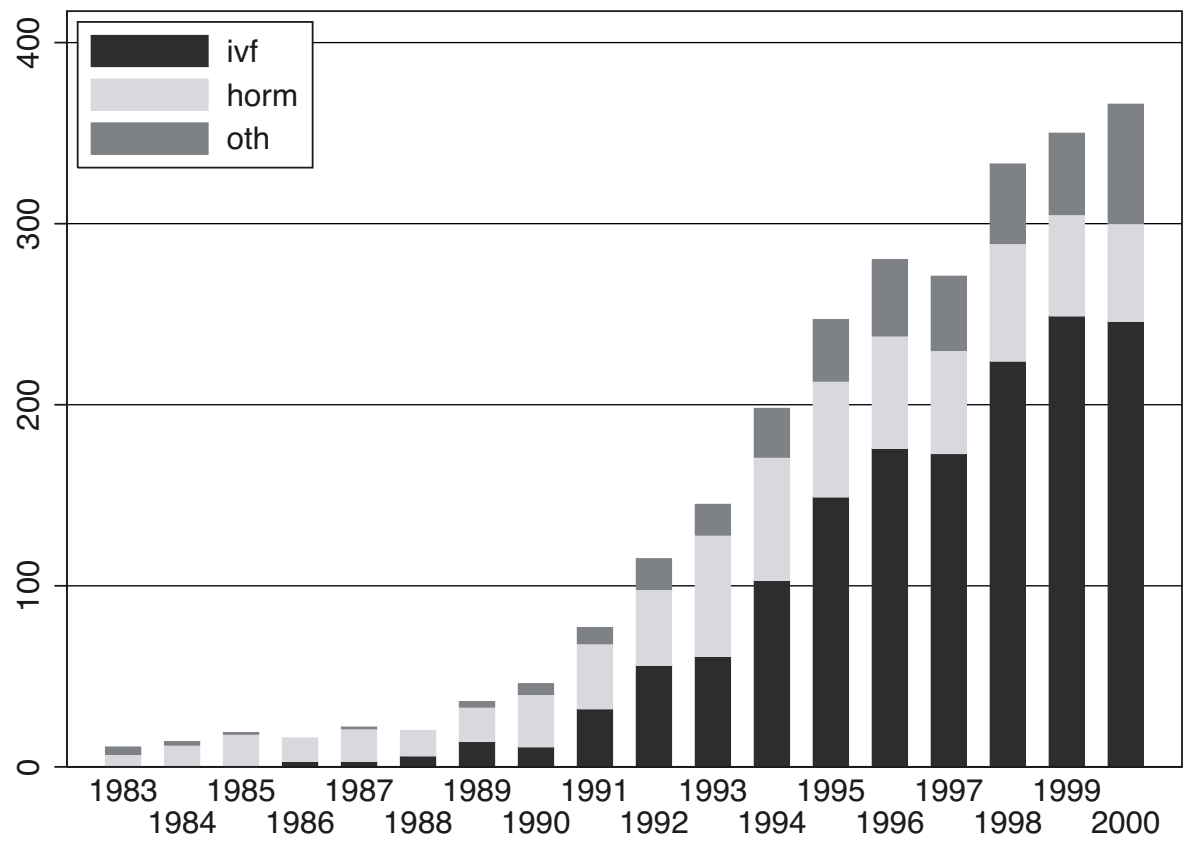

Figure 2

Number of twin births as a result of type of infertility treatment. Based on Twin Survey 2003.

Note: ivf = IVF/ICSI treatment; horm = Hormonal treatment; oth = other treatment of infertility. 


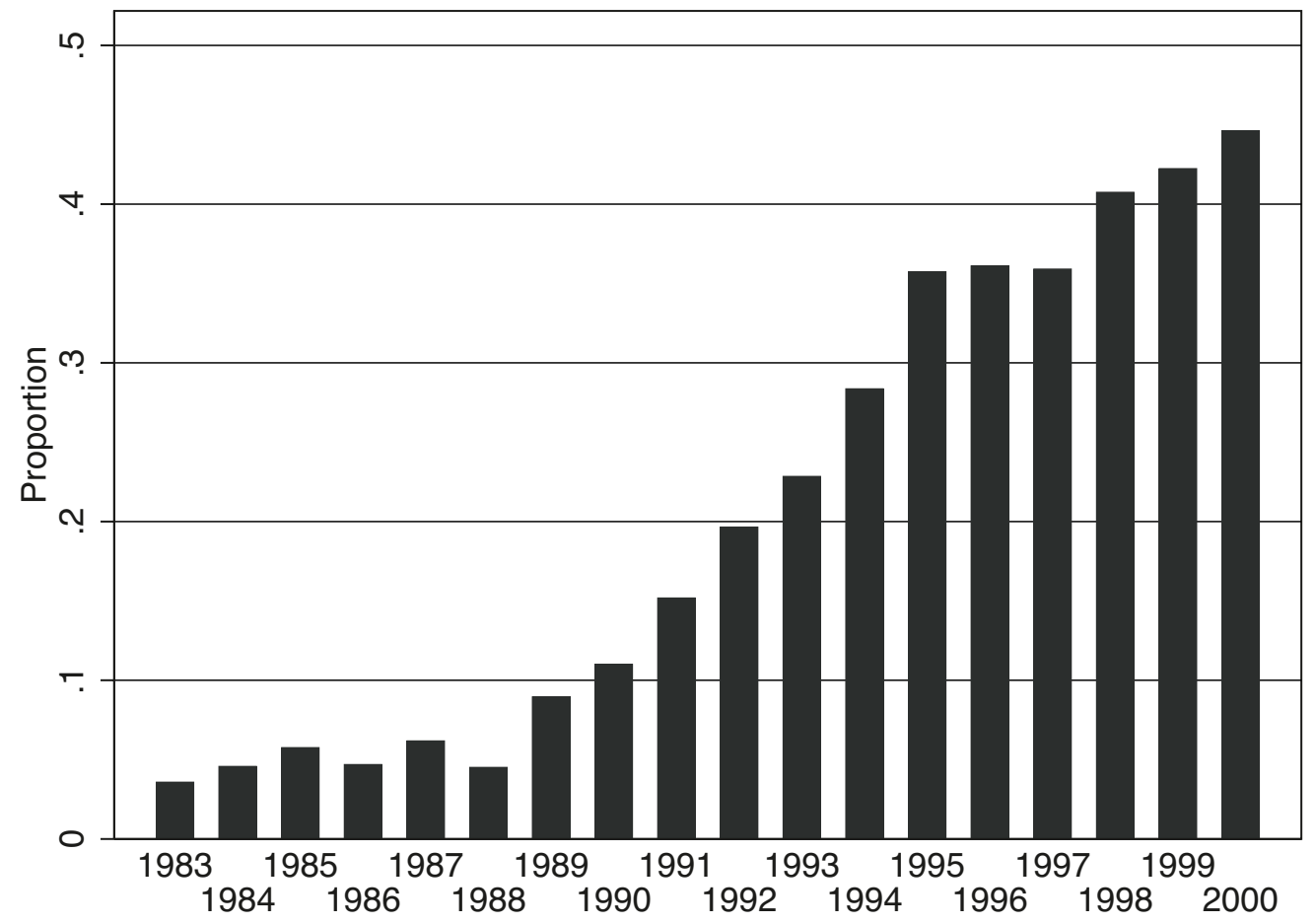

Figure 3

Proportion of twin births as result of infertility treatment.

Note: Based on Twin Survey 2003.

survey as particularly informative for a given research purpose, meaning that the survey was used as 'a screening instrument' for follow-up ancillary studies.

The Longitudinal Study of Aging Danish Twins (LSADT) is a longitudinal survey among Danish twins aged 70 years and older (Christensen, McGue et al., 2000). Every second year since 1995 twins have been visited by interviewers who go through the basically the same core questions and tests aimed at disentangling the genetic and environmental contribution to the physical and cognitive aging process. Although the structure of the interviews has been the same at all visits, a few new items have been added to the interview at each wave.

\section{Biological Material}

In the 1997 LSADT, full blood samples were obtained from a subset of 300 complete twin pairs, and in the 1999 LSADT survey, all nonproxy participants were asked to provide a DNA sample by means of a finger prick blood spot sample. The blood was stored on filter paper (Christensen, 2000). The blood spot sample was the preferred method of collecting DNA, however, the participants could provide biological material by using cheek brushes if they disliked a finger prick. A total of $90 \%$ of the nonproxy participants provided a biological sample of which $91 \%$ were blood spots. The same procedure was repeated in all subsequent waves (2001, 2003 and 2005) in order to study changes over time and to obtain more DNA.
The inclusion of blood spots/cheek brushes did not affect the participation rates in a negative way. Furthermore, more demanding measurements, such as grip strength and pulmonary functioning, were also included for the first time in 1999, still with no apparent influence on the participation rate.

\section{Age Dependent Gene Frequencies}

A very large number of candidate genes have been investigated for putative associations with human aging and longevity (Christensen, Johnson, et al., 2006). By combining the twin studies with parallel studies of elderly and oldest-old using the same instruments such as the longitudinal follow-up of the whole Danish 1905 cohort from age 92 to 93, it has become possible to study age-dependent gene frequency. The inference from an observation from such cross-sectional studies (e.g., that a fixed characteristic like a gene variant is decreasing in frequency with age) is dependent on a stable population with little migration into or out of the population, that is, no population stratification (Lewis \& Brunner, 2004). There was very little immigration in the cohorts older than 50 in Denmark often making Denmark well-suited for such cross-sectional age-dependency studies (also as a result of better preserved linkage disequilibrium between markers and putative causal mutations) compared to immigrant countries like United States and Australia.

An example of this use of cross-sectional data was a study of the gene for hereditary hemochromatosis, 
HFE. In northern European countries between 10 and $15 \%$ of the population are carriers of mutations in HFE. Initial findings showed that in our twin populations with high carrier frequencies, mutations in HFE showed an age-related reduction in the frequency of heterozygosity for the most common mutation C282Y, which suggested that carrier status is associated with shorter life expectancy (Bathum et al., 2001). However, enthusiasm was dampened by a large study concluding that the clinical penetrance even for homozygosity was less than $1 \%$ (Beutler et al., 2002). New data have, however, challenged these findings and suggested that the use of community genetic screening to prevent $H F E$-associated hereditary hemochromatosis is worthwhile (Delatycki et al., 2005). The potential small effect of the heterozygous state could still be considerable at the population level due to the high frequency of the mutation in many populations. The mutation is of special interest as venesection is an effective prevention of the clinical manifestations of the mutation.

\section{X-Inactivation}

Cross-sectional studies have shown that it is rare to have a skewed distribution of X-inactivation among younger females, while for females over the age of 60 , more than a third have a predominance of one of the cell lines in their blood, and among centenarians the majority of the females has a predominant cell line (Christensen, Kristiansen, et al., 2000). The skewed distribution in peripheral blood could be due to either depletion of hematopoietic stem-cells followed by random differentiation or selection processes based on $\mathrm{X}$-linked genetic factors.

It has been difficult to make animal experiments or human observations that could test the random versus selection hypotheses. The female twins, however, from whom full blood was obtained in the LSADT survey, provided an opportunity: If the often observed predominance of one of the two cell lines in peripheral blood in elderly females was determined by a stochastic process with no selection, one would expect little or no correlation in the $\mathrm{X}$-inactivation patterns between two MZ co-twins. A selection process based on X-linked genetic factors, on the other hand, would create a tendency for the same cell line to become predominant in two $\mathrm{MZ}$ co-twins. The peripheral blood cells from LSADT MZ female twins showed a strong tendency for the same cell line to become predominant in two co-twins which suggests that X-linked genetic factors influence human hematopoietic stem-cell kinetics and potentially the survival of the organism. The fact that females have two cell lines with different potentials could be one of the reasons why women live longer than men in all countries on the globe (Christensen, Kristiansen, et al., 2000).

\section{Gene Expression}

Microarray analyses in animal and humans of gene expression and changes with age are still few but many believe that a better understanding of gene expression will lead to insight into the mechanisms of aging. Three pairs of healthy $80+-$ year-old female MZ and $\mathrm{DZ}$ twins (six pairs in total) were identified from the LSADT study, and it was shown that even in this age group on this small sample a substantial genetic component to the variation in gene expression could be detected (Tan et al., 2006).

\section{A New Biological Indicator of Aging: Perceived Age}

In 2001 a new kind of phenotype was introduced to the LSADT survey: physical appearance. Twins have the quality of being of same biological age, but what about their physical appearance: Do they look the same age?

Modern medicine prefers 'objective' measures such as an increasing number of physiological parameters and increasingly sophisticated imaging tools. However, when assessing health, physicians in many countries traditionally still compare perceived and chronological age and make a note of this in the patient's record. Among adults, 'looking old for your age' is often interpreted as an indicator of poor health. Hence in the medical clinic, perceived age is used as a 'biomarker of aging' but little validation of this biomarker has been performed. The sparse data available on the relation between perceived age and survival indicate an inverse association (Christensen et al., 2004). It is not known whether 'looking old for your age' is primarily a result of lifestyle and other environmental factors or whether genetic factors play an important role.

The 2001 LSADT survey was used to determine the association between real age and perceived age and genetic and environmental factors in perceived age. In the study, $91 \%$ of cognitively intact participants agreed to have their picture taken (digital camera, 0.6 meter distance, neutral background, if possible). For a total of 387 same-sex twin pairs, high quality pictures of both twins were obtained (Figure 4). Twenty female nurses (aged 25-46) were engaged to estimate the twins' ages. The mean of the nurses' age estimates for each twin was used as the twin's perceived age, and the reliability of the mean age rating was .94. The correlation between real age and perceived age was .4 , while the correlation between the nurses' estimates for MZ twins $(r \approx .6, p<.01)$ was about twice the correlation for DZ twins $(r \approx .3, p<.01)$. This indicates an effect of additive genetic factors influencing perceived age. Biometrical models confirmed that the twin similarity is best explained by a model including additive genetic factors and nonfamily environment, and that the heritability (i.e., the proportion of the variance explained by genetic factors) of perceived age is about $60 \%$, with no sex or age differences.

By January 2003, nearly 2 years after the pictures were taken, one of the pictured twins in 49 pairs had 

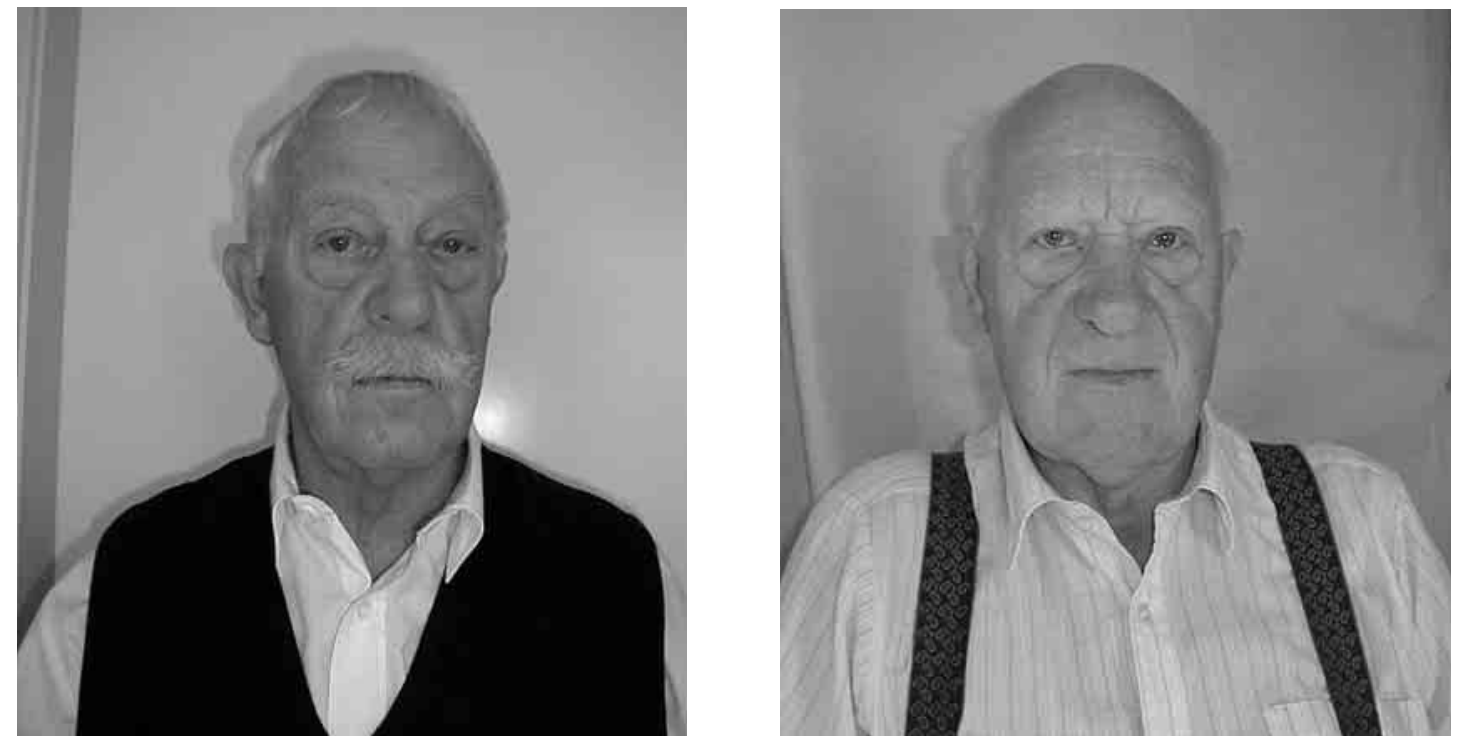

Figure 4

A monozygotic twin pair aged 71 years. Perceived age was 76.7 years (left twin with moustache) and 80.9 years (right twin).

died. Among these 49 pairs, the longer-surviving twin was rated as looking younger on average than his or her co-twin (mean of 1.15 years, $S D=3.63$, $t=2.22$ on $48 d f, p<.02$ ). This significant difference, however, owed entirely to those twin pairs who were perceived to be discrepant in age. A follow-up study of 5 years survival is currently being carried out (currently also using people of different age, gender, and education to estimate the age), and the preliminary analyses strongly support the initial findings.

The determinants of perceived age have also been studied using pictures of twins from both intact and broken twin pairs, and it was shown that factors like smoking, socioeconomic status, body mass index, marital status and depression-symptomatology all affect perceived age in the expected direction (Rexbye et al., 2006). Follow-up pictures were taken in 2003 and 2005, and, in addition, high-quality pictures of 100 selected pairs including facial imprint of the facial structure have been made. These studies have been performed to shed light on which immediate and distant factors are the basis for perceived age and its association with health and survival.

\section{Baldness}

In the 2001 LSDAT survey, digital photos of the vertex area of 739 elderly male twins, including 148 intact twin pairs, were obtained. These pictures were used to estimate the heritability of baldness among elderly men and to investigate if it correlates with perceived age.

Baldness (androgenetic alopecia) is the most common type of hair loss in men, and it has been established for younger men through studies on Australian twins that there is a strong genetic com- ponent to baldness (Nyholt et al., 2003); other studies have shown that it is associated with a higher perceived age among younger men.

At first glance the phenotype may not seem particularly important to study but hair is an important part of a person's physical appearance. The present cultural emphasis on youthful appearance has further strengthened the value of abundant hair. This emphasis is most likely why most men experience hair loss as a moderately stressful process, causing loss of self-esteem and impaired quality of life (Cash, 1992).

Five female nurses assessed the degree of baldness in each twin using a standardized instrument, where a vertex photo of each male twin was shown together with a scale of five categories. In addition, the scale included a category for nonclassifiable ('Don't know') if the nurse was in doubt (Figure 5). The intrapair correlation of degree of balding was consistently higher for $\mathrm{MZ}$ than for $\mathrm{DZ}$ twin pairs regardless of the baldness categorization used, and structural equation analysis revealed a heritability of $79 \%$ (95\% confidence intervals, $0.40-0.85)$ for the mean baldness index. The remaining variation could be attributed to nonshared environmental effects. There was only a very weak and statistically nonsignificant association between baldness and overestimation of age. The study concluded that the majority of the variation in baldness in elderly men - like in young men - could be explained by genetic factors, but also that hair quantity, contrary to the findings in young men, had little impact on perceived age in elderly men (Rexbye et al., 2005). 


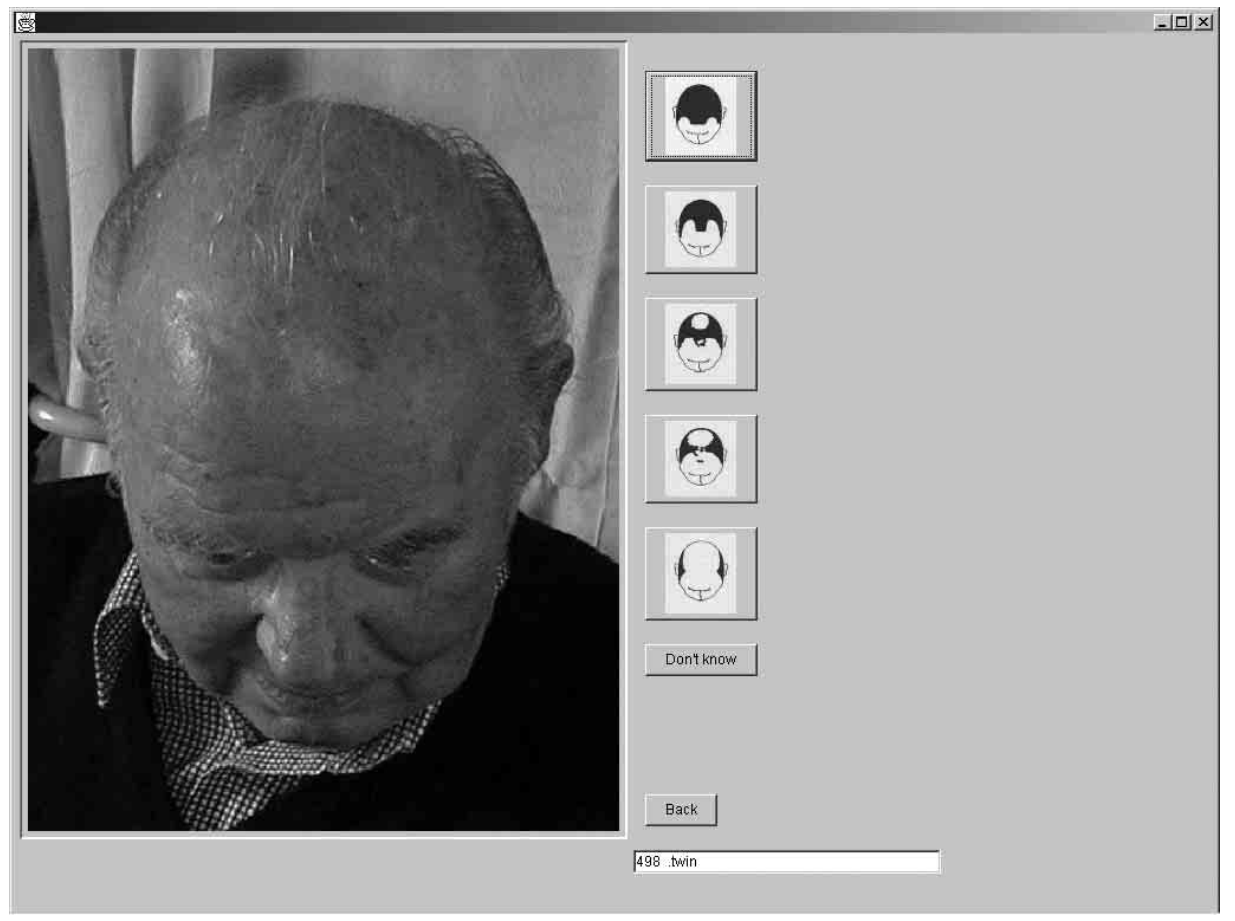

Figure 5

Screen for evaluating baldness.

\section{Register-Based Studies - New Possibilities and Future Plans}

From an epidemiological viewpoint, Denmark is blessed with the unique personal identification number (PIN), which has been assigned to all Danish residents since April 2, 1968, and is managed by the Danish Civil Registration System. The PIN is used almost every time a person interacts with authorities, for example tax payments, social benefits, health care system, and the educational system. Thus it is possible to access research data at the individual level. For many years it has been possible to link individuals to a number of registers with information about diseases, maintained by private organisations (e.g. the Danish Cancer Registry) or by official authorities (e.g., the National Register of Patients, Medical Birth Register), and a number of studies have emerged utilizing these possibilities (e.g., Hansen et al., 2005; Larsen et al., 2003, 2004; Tveskov et al., 2005). During the last 5 years a new field has been added, since the national statistical bureau of Denmark, Statistics Denmark, has presented the possibility to link external data with the internal registers held by Statistics Denmark at the individual level.

The DTR has initiated a series of research projects utilizing this new possibility at the intersection of fertility, socioeconomic factors, and genetics. As the first step a dataset, which combines a number of variables from various registers, has been created for the core population of twins and a $5 \%$ sample of the general population born between 1880 and 2000. The dataset includes variables from the labor market database, educational attainment, tax-orientated income statistics, social statistics, housing register, national hospital discharge register, demographic database, and the national civil registration system. Furthermore zygosity information from the DTR has been added for the twins.

The combined dataset with both the twins and the $5 \%$ sample of the total population provides a unique opportunity to test the often-debated question to what extent twins can be considered similar to singletons (Christensen, Petersen, et al., 2006). One of the first applications of the created dataset has been to investigate whether twins have a similar school performance in adolescence as singletons for the birth cohorts 1986-1988. Since 2001, information about school performance in the 9 th grade (corresponding to the age $15-16$ years) has been available in Statistics Denmark. In addition, birthweight could be obtained from the demographic database together with information about the educational status of the parents. The study sample comprised 3711 twins and 7796 singletons. Within the group of twins and among singletons a weak but significantly positive association between birthweight and school performance was found, in accordance with results from other population studies (Matte et al., 2001). However, despite a difference in birthweight of 900 grams between singletons and twins, the twins $(M=8.02, S D=1.05)$ performed equally well as the singletons $(M=8.02, S D=1.06)$, and the similarity persisted even after controlling for birthweight, gestational age at birth, age at test as well as parental 
age and education. This finding indicates that being a twin does not imply a cognitive disadvantage in recent Danish cohorts, contrary to results from older cohorts (Deary et al., 2005; Ronalds et al., 2005).

The possibility to link external data with internal databases in Statistics Denmark provides a unique opportunity to overcome some of the weaknesses in interview and questionnaire-based surveys. Although the willingness of twins to participate in such surveys is great, the nonparticipants (typically between 15 and $35 \%$ ) are not a random sample of the population under study. Especially among the elderly the sick and most disabled tend to refuse participation, and hence the validity of the studies are challenged. By linking information obtained from surveys to the registers in Statistics Denmark it becomes possible to compare the participants with the nonparticipants and to correct for this in the analyses and in the interpretation of the survey results. In addition, the reliability of certain kinds of information may increase by using the register information, especially information that requires a good memory about hospitalization, diagnoses and medication, a challenge to elderly people.

\section{$\overline{\text { Acknowledgments }}$}

We want to thank the following for their considerable financial contribution to the foundation and the continued support of the Danish Twin Registry: the Danish Research Council, University of Southern Denmark, the Danish National Research Foundation, Helsefonden, the Danish Diabetic Association, the Danish Heart Foundation, the Novo Nordisk Foundation, Unilever, the Velux Foundation, and the United States National Institute on Aging (P01AG08761).

\section{References}

Bathum, L., Christiansen, L., Nybo, H., AndersenRanberg, K., Gaist, D., Jeune, B., Petersen, N. E., Vaupel, J. W., \& Christensen, K. (2001). Association of mutations in the hemochromatosis gene with shorter life expectancy. Archives of Internal Medicine, 16, 2441-2444.

Beutler, E., Felitti, V. J., Koziol, J.A., Ho, N. J., \& Gelbart, T. (2002). Penetrance of $845 \mathrm{G}-\mathrm{A}(\mathrm{C} 282 \mathrm{Y})$ HFE hereditary haemochromatosis mutation in the USA. Lancet, 359, 211-218.

Cash, T. F. (1992). The psychological effects of androgenetic alopecia in men. Journal of the American Academy of Dermatology, 26, 926-931.

Christensen, K. (2000). Biological material in household surveys: The interface between epidemiology and genetics. In C. E. Finch, J. W. Vaupel, \& K. Kinsella (Eds.), Cells and surveys: Should biological measures be included in social science research? Commission on Behavioral and Social Sciences and Education, National Research Council (pp. 42-63). Washington DC: National Academy Press.
Christensen, K., Iachina, I., Rexbye, H., Tomassini, C., Frederiksen, H., McGue, M., \& Vaupel, J.W. (2004). Looking old for your age: Genetics and mortality [Letter]. Epidemiology, 15, 251-252.

Christensen, K., Johnson, T. E., \& Vaupel, J.W. (2006). The quest for genetic determinants of human longevity: Challenges and insights. Nature Reviews. Genetics, 7, 436-448.

Christensen, K., Kristiansen, M., Hagen-Larsen, H., Skytthe, A., Bathum, L., Jeune, B., Andersen-Ranberg, K., Vaupel, J. W., \& Orstavik, K. H. (2000). X-linked genetic factors regulate hematopoietic stem-cell kinetics in females. Blood, 95, 2449-2451.

Christensen, K., McGue, M., Yashin, A., Iachine, I., Holm, N., \& Vaupel, J. (2000). Genetic and environmental influences on functional abilities in Danish twins aged 75 years and older. Journals of Gerontology Series A-Biological Sciences and Medical Sciences, 55, M446-M452.

Christensen, K., Petersen, I., Skytthe, A., Herskind, A.M., McGue, M., \& Bingley, P. (2006). Birthweight in twins and singletons and school performance in adolescence: A follow-up study [Electronic version]. British Medical Journal, DOI 10.1136/bmj.38959. 650903.7C.

Christiansen, L., Frederiksen, H., Schousboe, K., Skytthe, A., von Wurmb-Schwark, N., Christensen, K., \& Kyvik, K. (2003). Age- and sex-differences in the validity of questionnaire-based zygosity in twins. Twin Research, 6, 275-278.

Deary, I., Pattie, A., Wilson, V., \& Whalley, L. (2005). The cognitive cost of being a twin: Two whole-population surveys. Twin Research and Human Genetics, 8, 376-383.

Delatycki, M. B., Allen, K. J., Nisselle, A. E., Collins, V., Metcalfe, S., du-Sart, D., Halliday, J., Aitken, M. A., Macciocca, I., Hill, V., Wakefield, A., Ritchie, A., Gason, A. A., Nicoll, A. J., Powell, L. W., \& Williamson, R. (2005). Use of community genetic screening to prevent HFE-associated hereditary haemochromatosis. Lancet, 366, 314-316.

Engell, V., Damborg, F., Andersen, M., Kyvik, K. O., \& Thomsen, K. (2006). Club foot: A twin study. The Journal of Bone and Joint Surgery. British Volume, 88, 374-376.

Fejer, R., Hartvigsen, J., \& Kyvik, K. O. (2006). Heritability of neck pain: A population-based study of 33,794 Danish twins. Rheumatology, 45, 589-594.

Hansen, P. S., Brix, T. H., Sørensen, T. I. A., Kyvik, K. O., $\&$ Hegedüs, L. (2004). Major genetic influence on the regulation of the pituitary-thyroid axis: A study of healthy Danish twins. Journal of Clinical Endocrinology \& Metabolism, 89, 1181-1187.

Hansen, T., Skytthe, A., Stenager, E., Petersen, H. C., Brønnum-Hansen, H., \& Kyvik, K. O. (2005). Concordance for multiple sclerosis in Danish twins: 
An update of a nationwide study. Multiple Sclerosis, 11, 504-510.

Hauge, M. (1981). The Danish Twin Register. In S. A. Mednick, A. E. Baert, \& B. P. Bachmann (Eds.), Prospective longitudinal research. An empirical basis for the primary prevention of psychosocial disorders (pp. 217-221). Oxford: Oxford University Press.

Herskind, A. M., Basso, O., Olsen, J., Skytthe, A., \& Christensen, K. (2005). Is the natural twinning rate still declining? [Letter]. Epidemiology, 16, 591-592.

Kohler, H. P., Behrman, J. R., \& Skytthe, A. (2005). Partner + children $=$ happiness? The effects of partnerships and fertility on well-being. Population and Development Review, 31, 407-445.

Larsen, T. B., Sørensen, H. T., Skytthe, A., Johnsen, S. P., Vaupel, J. W., \& Christensen, K. (2003). Major genetic susceptibility for venous thromboembolism in men: A study of Danish twins. Epidemiology, 14, 328-332.

Laursen, M., Bille, C., Olesen, A.W., Hjelmborg, J., Skytthe, A., \& Christensen, K. (2004). Genetic influence on prolonged gestation: A population-based Danish twin study. American Journal of Obstetrics and Gynecology, 190, 489-494.

Lewis, S. J., \& Brunner, E. J. (2004). Methodological problems in genetic association studies of longevity The apolipoprotein E gene as an example. International Journal of Epidemiology, 33, 962-970.

Matte, T. D., Bresnahan, M., Begg, M. D., \& Susser, E. (2001). Influence of variation in birthweight within normal range and within sibships on IQ at age 7 years: Cohort study. British Medical Journal, 323, 310-314.

Nyholt, D. R., Gillespie, N. A., Heath, A. C., \& Martin, N. G. (2003). Genetic basis of male pattern baldness. Journal of Investigative Dermatology, 121, 1561-1564.

Pinborg, A., Loft, A., Rasmussen, S., Schmidt, L., Langhoff-Roos, J., Greisen, G., \& Nyboe-Andersen,
A. (2004). Neonatal outcome in a Danish national cohort of 3438 IVF/ICSI and 10,362 non-IVF/ICSI twins born between 1995 and 2000. Human Reproduction, 19, 435-441.

Rexbye, H., Petersen, I., Iachina, M., Mortensen, J., McGue, M., Vaupel, J. W., \& Christensen, K. (2005). Hair loss among elderly men: Etiology and impact on perceived age. Journals of Gerontology Series A-Biological Sciences and Medical Sciences, 60, 1077-1082.

Rexbye, H., Petersen, I., Johansen, M., Klitkou, L., Jeune, B., \& Christensen, K. (2006). Influence of environmental factors on facial ageing. Age and Ageing, 35, 110-115.

Ronalds, G. A., De Stavola, B. L., \& Leon, D. A. (2005). The cognitive cost of being a twin: evidence from comparisons within families in the Aberdeen children of the 1950s cohort study. British Medical Journal, 331, 1306.

Schousboe, K., Visscher, P. M., Henriksen, J. E., Hopper, J. L., Sørensen, T. I. A., \& Kyvik, K. O. (2003). Twin study of genetic and environmental influences on glucose tolerance and indices of insulin sensitivity and secretion. Diabetologia, 46, 1276-1283.

Skytthe, A., Kyvik, K., Holm, N. V., Vaupel, J. W., \& Christensen, K. (2002). The Danish twin registry: 127 birth cohorts of twins. Twin Research, 5, 352-357.

Tan, Q., Kruse, T. A., \& Christensen, K. (2006). Design and analysis in genetic studies of human ageing and longevity. Ageing Research Reviews, 5, 371-387.

Tveskov, C., Skytthe, A., Arnsbo, P., Vaupel, J. W., Møller, M., \& Christensen, K. (2005). Twins with implanted pacemakers: Is there an increased mortality risk for the co-twin? A follow-up study based on the Danish Twin Registry and the Danish Pacemaker Register. Europace, 7, 598-603. 